\title{
Declining incidence of severe retinopathy and persisting decrease of nephropathy in an unselected population of Type 1 diabetes- the Linköping Diabetes Complications Study
}

\author{
M. Nordwall ${ }^{1,6}$ • M. Bojestig 2,3 • H. J. Arnqvist ${ }^{4} \cdot$ J. Ludvigsson ${ }^{5}$ \\ ${ }^{1}$ Division of Paediatrics and Diabetes Research Centre, Department of Molecular and Clinical Medicine, University Hospital, \\ Linköping, Sweden \\ ${ }^{2}$ Division of Internal Medicine and Diabetes Research Centre, Department of Medicine and Care, University Hospital, Linköping, \\ Sweden \\ ${ }^{3}$ Department of Medicine, Eksjö Hospital, Eksjö, Sweden \\ ${ }^{4}$ Division of Internal Medicine and Diabetes Research Centre, Department of Medicine and Care, University Hospital, Linköping, \\ Sweden \\ ${ }^{5}$ Division of Paediatrics and Diabetes Research Centre, Department of Molecular and Clinical Medicine, University Hospital, \\ Linköping, Sweden \\ ${ }^{6}$ Division of Paediatrics, Department of Molecular and Clinical Medicine, Faculty of Health Science, Linköping, Sweden
}

\begin{abstract}
Aims/hypothesis. In a previous study conducted over the last decades we found a decreased incidence of nephropathy but unchanged incidence of severe retinopathy among patients with Type 1 diabetes diagnosed in childhood and with 20 years duration of diabetes. The aim of our current study was to investigate the incidence 5 to10 years later in the same population. Methods. We studied all 269 patients in whom Type 1 diabetes was diagnosed in childhood between 1961 and 1985 in a district in southeastern Sweden. Ninetyone percent were monitored for retinopathy until at least 1997 and 95\% were monitored for nephropathy. Severe retinopathy was defined as laser-treated retinopathy and nephropathy as persistent proteinuria. Survival analysis was used and the patients divided into five cohorts according to the time of onset of diabetes.
\end{abstract}

Results. The cumulative proportion of severe retinopathy had declined $(p=0.006)$. After 25 years it was $47 \%$ (95\% CI 34-61), 28\% (15-40) and 24\% (12-36) in the cohorts 1961 to 1965,1966 to 1970 and 1971 to 1975 respectively. After 30 years it was 53\% (40-66) and 44\% (28-59) in the oldest cohorts. The cumulative proportion of nephropathy after 25 years duration was $30 \%(18-42), 8 \%(1-16)$ and $13 \%(4-23)$ in the cohorts 1961 to 1965,1966 to 1970 and 1971 to 1975 respectively. After 30 years, it was $32 \%(20-44)$ and $11 \%$ (2-20) for the oldest cohorts $(p<0.0001)$.

Conclusions/interpretation. In an unselected population with Type 1 diabetes diagnosed in childhood, modern diabetes care markedly reduced the incidence of severe retinopathy and nephropathy.

Keywords Diabetic nephropathy $\cdot$ Diabetic retinopathy $\cdot$ Incidence $\cdot$ Population $\cdot$ Type 1 diabetes mellitus
Received: 30 January 2004 / Accepted: 19 April 2004

Published online: 2 July 2004

C Springer-Verlag 2004

M. Nordwall ( $)$

Division of Paediatrics,

Department of Molecular and Clinical Medicine,

Faculty of Health Science, 58183 Linköping, Sweden

E-mail: Maria.Nordwall@lio.se

Tel.: +46-11-222000, Fax: +46-11-223735

Abbreviations: SMR, standardised mortality ratio
Over the last few decades, several improvements in diabetes care have been made. Long-term monitoring of glycaemic control by $\mathrm{HbA}_{1} \mathrm{c}$ was introduced [1] as well as patient education, self-monitoring of blood glucose [2], insulin treatment with basal-bolus concept, insulin pens and continuous subcutaneous insulin infusion with insulin pumps [3]. In several randomised clinical trials improved glycaemic control has been found to reduce the development of retinopathy and nephropathy $[4,5,6,7]$. There has, however, been a debate about whether it is possible to achieve the same results in an unselected population. 
In the Linköping Diabetes Complications Study we observed a marked decline in the incidence of diabetic nephropathy, from $28 \%$ to $9 \%$ after 20 years of diabetes, in an unselected population of Type 1 diabetes diagnosed between 1961 and 1980 [8]. However, we could not find a significant decrease of severe, lasertreated retinopathy [9]. A possible explanation is that the improvements in diabetes care were sufficient to prevent nephropathy but not retinopathy. Another explanation is that the follow-up was too short to detect a declining trend of retinopathy. In the DCCT study there was a delay of 3 years from the introduction of improvements in metabolic control until the incidence of retinopathy had decreased $[5,10]$.

The aim of our study was to investigate whether it is possible to detect a decreased incidence of retinopathy when we follow the same population for another 5 to 10 years. An important question is also whether we have prevented and not merely postponed diabetic nephropathy. Has the decreased incidence of nephropathy persisted?

\section{Subjects and methods}

Patients. We studied all 269 patients with Type 1 diabetes who were diagnosed before age 15 between 1961 and 1985 and who lived in the catchment area of the Paediatric Clinic, University Hospital, Linköping, Sweden. These patients represent the total population of newly diagnosed diabetes, as every child with diabetes in Sweden is treated at a paediatric clinic. Of the total population, $244(90.7 \%)$ were monitored for retinopathy and 255 (94.8\%) for nephropathy until at least 1997. The remaining patients were followed until their most recent clinical visit. Three patients moved abroad within 5 years after diabetes diagnosis. Twelve patients died before developing retinopathy and seven patients died before developing nephropathy. For $214(80 \%)$ patients, information was available in the patients' records in the catchment area. For the other patients, who had left the area, information was collected by a questionnaire through their physicians after written consent was given by the patient.

For the analysis, the patients were divided into five groups according to the year in which diabetes was diagnosed: 1961 to 1965,1966 to 1970,1971 to 1975,1976 to 1980 and 1981 to
1985. The groups were similar in number of patients, patients still living in the catchment area, sex distribution, mean age at onset of diabetes, proportion diagnosed before puberty, and percentage followed (Table 1).

During the 1960s, the standard regimen was a single dose of long-acting insulin in the morning. In the 1970s, a diabetes team with doctors, nurses, dieticians, psychologists and social workers was introduced at the paediatric clinic. Good metabolic control was emphasised from the beginning. Regular selfmonitoring of urine glucose three times daily became routine in 1971 and self-monitoring of blood glucose was standard by 1980. The number of daily insulin injections increased gradually during the 1970s and 1980s to four or five injections with a combination of short-acting and long-acting insulin. In the 1990s several patients used insulin pumps. The same routines were followed and the goal of therapy remained the same when at the age of 18 to 20 years the patients were transferred to the Department of Internal Medicine. One fifth of the patients had moved between one and several years after diabetes diagnosis was made. The insulin regimens and main goal of treatment have been about the same in other hospitals in Sweden over the past few decades, even if there are minor differences in management of diabetes.

The Research Ethics Committee of the Faculty of Health Sciences, Linköping University approved the study.

Definition of retinopathy. The patients were screened regularly, every second year, for retinopathy after the beginning of puberty (defined as 11 years of age for girls and 12 years of age for boys). The screening was done up to the 1970s with ophthalmoscopy and later on with colour fundus photography. Three photos were taken nasally, on the macula and on the optic nerve of each eye with a photo angle of $45^{\circ}$. After 1995 , the pictures were digitalised with two photos of each eye (macula and optic nerve). An additional three photos were taken if there was any abnormal finding. All photos were examined by an ophthalmologist and categorised using a standard protocol into four classes on the basis of the eye with the greatest damage, namely into: normal, background retinopathy, preproliferative retinopathy and proliferative retinopathy. The presence of macular oedema was also noted. The patients who had left the catchment area were examined in their local hospital. The follow-up didn't differ substantially between different hospitals around the country, since over the last few decades there has been a national consensus in Sweden concerning methods for screening and advisable time intervals. The same grading system was used, but the definitions were determined locally. The information was collected from the patient charts through their physicians.

Table 1. Clinical characteristics of patients with Type 1 diabetes diagnosed in childhood

\begin{tabular}{lcllllllr}
\hline $\begin{array}{l}\text { Period of } \\
\text { onset }\end{array}$ & $n^{\mathrm{a}}$ & Male & Age at onset & $\begin{array}{l}\text { Onset } \\
\text { before } \\
\text { puberty }\end{array}$ & $\begin{array}{l}\text { Patients dead } \\
\text { before } \\
\text { developing } \\
\text { retinopathy } \\
n\end{array}$ & $\begin{array}{l}\text { Patients dead } \\
\text { before } \\
\text { developing } \\
\text { nephropathy } \\
n\end{array}$ & $\begin{array}{l}\text { Patients } \\
\text { followed } \\
\text { until 1997 } \\
\text { retinopathy } \\
n(\%)\end{array}$ & $\begin{array}{l}\text { Patients } \\
\text { followed } \\
\text { until 1997 } \\
\text { nephropathy } \\
n(\%)\end{array}$ \\
\hline $1961-1965$ & $56(44)$ & 41.1 & $8.5(3.5)$ & 71.4 & 3 & 1 & $52(92.9)$ & $55(98.2)$ \\
$1966-1970$ & $50(40)$ & 48.0 & $8.0(3.9)$ & 76.0 & 4 & 1 & $43(86.0)$ & $48(96.0)$ \\
$1971-1975$ & $55(41)$ & 52.7 & $8.8(4.0)$ & 60.0 & 2 & 2 & $52(94.5)$ & $52(94.5)$ \\
$1976-1980$ & $51(40)$ & 39.2 & $8.7(3.8)$ & 68.6 & 2 & 2 & $47(92.2)$ & $49(96.1)$ \\
$1981-1985$ & $57(49)$ & 56.1 & $8.9(3.8)$ & 63.2 & 1 & 1 & $50(87.7)$ & $51(89.5)$ \\
All periods & $269(214)$ & 52.4 & $8.6(3.8)$ & 67.7 & 12 & 7 & $244(90.7)$ & $255(94.8)$ \\
\hline
\end{tabular}

${ }^{\mathrm{a}}$ In brackets number of patients still living in the catchment area 
The onset of severe retinopathy was defined as the date of the first laser treatment. The indications were proliferative retinopathy or macular oedema.

The prevalence of non-proliferative retinopathy was calculated from data at the last fundus photography and compared with the prevalence at the previous follow-up in 1990. There were in mean 7.6 (SD 1.2) years between these examinations. All grades from milder forms of background retinopathy to preproliferative changes were included; (for the youngest cohort there were no data from 1990).

Definition of nephropathy. All patients were tested for proteinuria at their regular clinic visits with a semi-quantitative test strip (Albustix, Combur, Redia or equivalent strips). During the last few decades the patients also had a morning sample of urine analysed by a quantitative method, either as a timed overnight analysis or as a spot test. Diabetic nephropathy was defined in this study as persistent proteinuria, that is, at least $1+$ test result (which corresponds to an albumin concentration in the urine of $\geq 300 \mathrm{mg} / \mathrm{l}$ ) or with a quantitative method albumin excretion rate of $200 \mu \mathrm{g} / \mathrm{min}$ or more or an albumin concentration of $300 \mathrm{mg} / \mathrm{l}$ or more. The onset of diabetic nephropathy was defined as the first year during which proteinuria became persistent.

Microalbuminuria was measured regularly, at least once every year. The prevalence of microalbuminuria was measured in 1990 and at the last clinic visit (for the youngest cohort diagnosed between 1981 and 1985 there were no data from 1990). There were on average 8.0 (SD 1.6) years between these investigations. For patients still living in the catchment area, the urine was analysed as a timed overnight urine sample with an immunoturbidometry method at the local hospital laboratory. For patients moving away to other parts of the country, analyses were made at the local hospitals with a quantitative method, but in a few cases with a semi-quantitative method (Micral test). Microalbuminuria was defined as an albumin excretion rate of 20 to $200 \mu \mathrm{g}$ of albumin per min or an albumin concentration of 30 to $299 \mathrm{mg} / \mathrm{l}$.

Statistical analysis. The cumulative proportion of retinopathy and nephropathy was calculated for one-year intervals using a life table method that took into account differences in the interval of follow-up after diagnosis. Patients, who have not developed any complications, contributed to the follow-up until their last clinic visit or to the year of death. The differences between all the groups and pair-wise comparisons were tested using the Wilcoxon (Gehan) statistic test. A $p$ value of less than 0.05 was considered statistically significant [11]. The calculations were done using the SPSS Statistical Package for Social Science.

The prevalence rate ratio was calculated in each cohort for the prevalence of non-proliferative retinopathy and microalbuminuria among the patients still not affected by severe retinopathy and nephropathy respectively. The chi square or Fischer's exact test was used to test for significance. Data for the prevalence comparison were analysed using Epiinfo2002. The ageadjusted standardised mortality ratio (SMR) was calculated using the general population in Sweden as reference population.

\section{Results}

The cumulative proportion of severe retinopathy began to increase after 10 years of diabetes. After 25 years duration it was $47.3 \%$ (95\% CI 34.1-60.5) in the oldest cohort with diabetes diagnosis between 1961

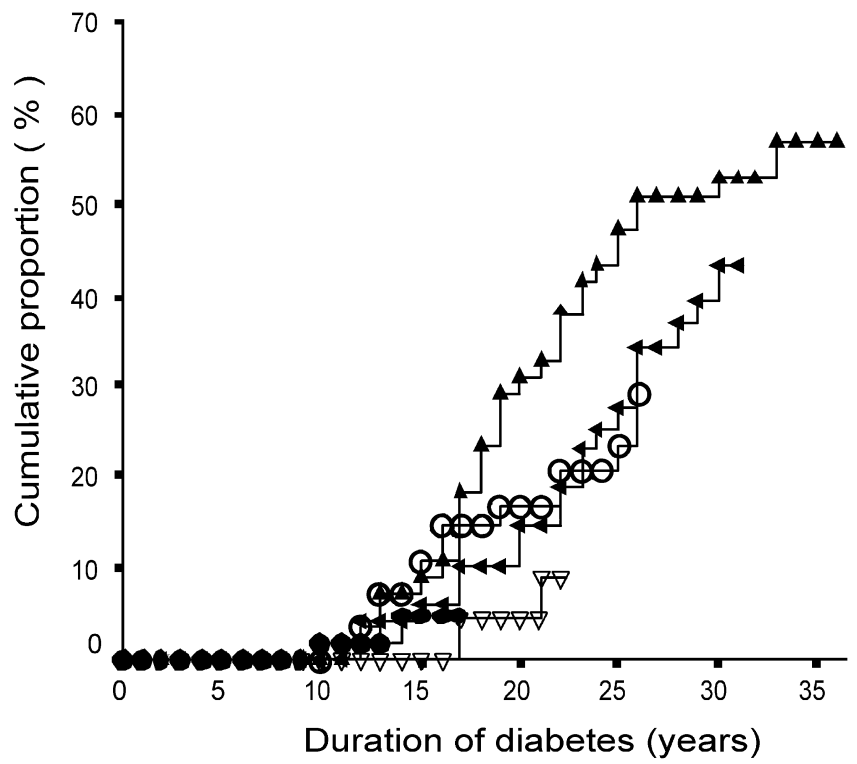

Fig. 1. Cumulative proportion of severe (laser-treated) retinopathy in a population of patients with Type 1 diabetes diagnosed before the age of 15 years according to the year of onset of diabetes. Onset of diabetes: 1961-1965 $\Delta, 1966-1970<(p=0.08)$, 1971-1975 $\bigcirc(p=0.03), 1976-1980 \nabla(p=0.001), 1981-1985$ ( $(p=0.23) . p=0.006$ for overall comparison of all groups. The $p$ values between the oldest cohort (onset 1961-1965) and the following cohorts are indicated in brackets

and 1965 . In the cohort 1966 to 1970 there was a declining trend to $27.6 \%$ (14.8-40.4). In the cohort 1971 to 1975 it had decreased further to $23.6 \%$ (11.6-35.6). After 30 years the cumulative proportion had increased to $52.8 \%(39.6-66.0)$ in the oldest cohort and in the next cohort 1966 to 1970 to $43.5 \%$ (28.1-58.9). In the next youngest cohort there were just three cases, two cases after 17 years duration and one case after 21 years duration. In the youngest cohort there were two cases after 10 and 14 years disease duration respectively. In overall comparison there was a significant declining trend between the groups $(p=0.006)$. The decrease was significant between the oldest cohort and the cohorts 1971 to 1975 and 1976 to 1980 . The other differences were not significant (Fig. 1).

The prevalence of non-proliferative retinopathy was high in all groups, and after mean diabetes duration of 25 years, more than $80 \%$ of the patients had non-proliferative changes in their eyes. The cohort with onset between 1971 and 1975 deteriorated between the two occasions of follow-up and for the cohort 1976 to 1980 the trend was similar (Fig. 2a).

The cumulative proportion of nephropathy began to increase after 8 years of diabetes. The cumulative proportion reached $30.3 \%$ (95\% CI 18.3-42.3) in the oldest cohort after 20 years of diabetes. The proportion had declined to $8.2 \%(0.5-15.9)$ and $9.2 \%$ (1.5-16.9) respectively in the following cohorts. After 25 years duration of the disease, there were just a few new cases and the proportion of nephropathy was 
a

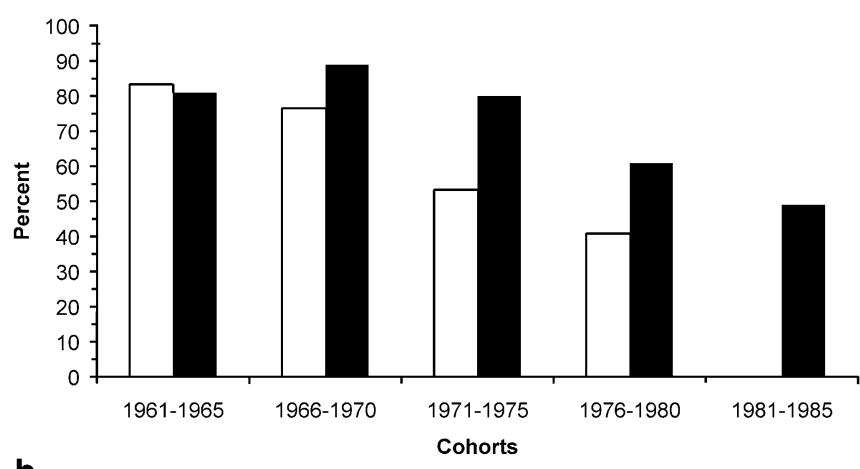

b

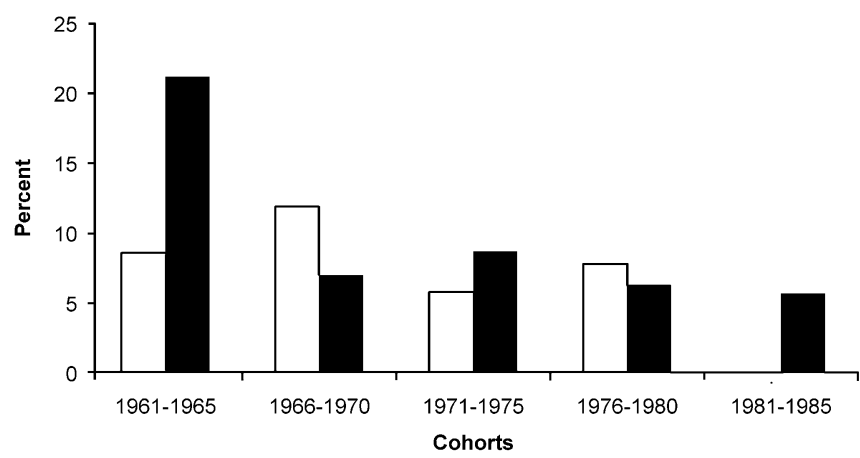

Fig. 2. Prevalence of (a) non-proliferative retinopathy and (b) microalbuminuria in 1990 (open bars) and at the last follow-up after 1997 (black bars) among patients diagnosed with Type 1 diabetes before the age of 15 years. Values are presented according to the year of onset of diabetes. a. Relative risk (RR), according to years of onset, with $95 \%$ confidence interval: 1961-1965, RR=0.92 (CI: 0.42-2.00); 1966-1970, RR=1.76 (CI: 0.64-4.82); 1971-1975, RR=2.07 (CI: 1.10-3.90); 19761980, RR=1.52 (CI: 0.99-2.35). Number of patients 1990 follow-up (from left to right): $n=20, n=26, n=24, n=20$. Number of patients, post-1997 (from left): $n=17, n=24, n=32, n=28, n=25$. b. Relative risk (RR), according to years of onset, with $95 \%$ confidence interval: 1961-1965, RR=1.56 (CI: 0.95-2.56); 1966-1970, RR=0.72 (CI: 0.29-1.81); 1971-1975, RR=1.24 (CI: 0.63-2.44); 1976-1980, RR=0.88 (CI: 0.36-2.11). Number of patients 1990 follow-up (from left to right): $n=3, n=5, n=3$, $n=4$. Number of patients, post-1997 (from left): $n=7, n=3, n=4$, $n=3, n=3$

$30.3 \% \quad(18.3-42.3), 8.2 \% \quad(0.5-15.9)$ and $13.3 \%$ (4.1-22.5) respectively for the three oldest cohorts. The difference between the two oldest cohorts persisted even after 30 years duration with a cumulative proportion of $32.1 \%(19.9-44.3)$ in the 1961 to 1965 cohort compared to $10.8 \%(1.8-19.8)$ in the 1966 to 1970 cohort $(p=0.005)$. In the cohort 1976 to 1980 there was just one case of nephropathy after 18 years duration and in the youngest cohort there was also just one case after 13 years duration. When all groups were compared there was a significant decrease of nephropathy $(p<0.0001)$. There was a significant decrease between the oldest cohort and all the following cohorts, but no significant difference between the other cohorts (Fig. 3).

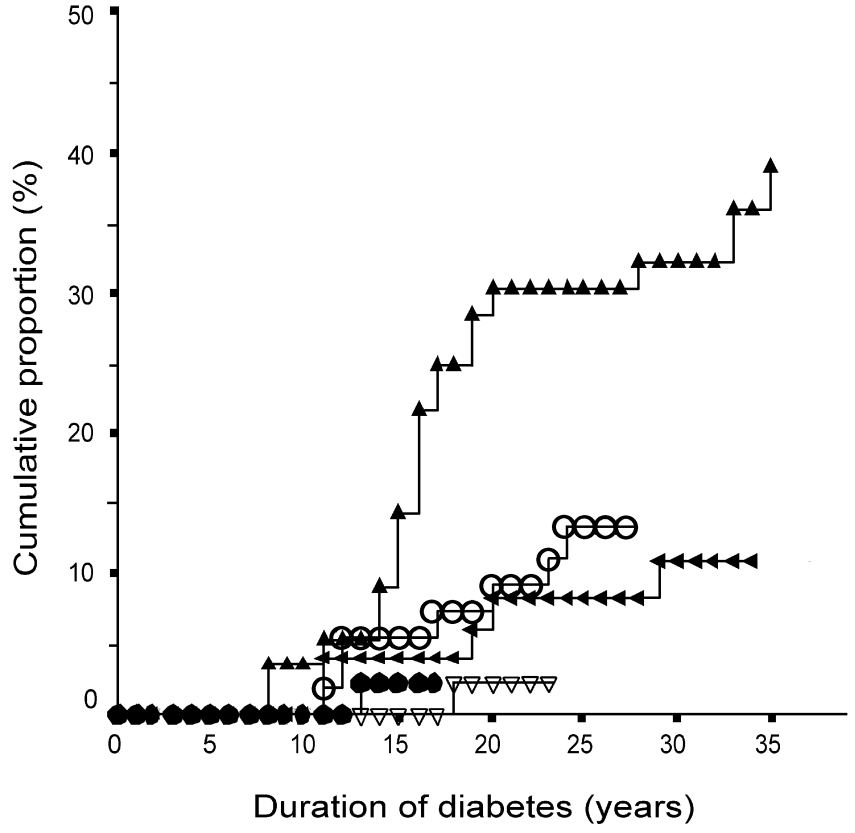

Fig. 3. Cumulative proportion of diabetic nephropathy in a population of patients with Type 1 diabetes diagnosed before the age of 15 years, according to the year of onset of diabetes. Onset of diabetes: 1961-1965 $\boldsymbol{\Delta}, 1966-1970<(p=0.005)$, $1971-1975 \bigcirc(p=0.02), 1976-1980 \nabla(p<0.001), 1981-1985$ ( $(p=0.02) . p<0.001$ for overall comparison of all groups. The $p$ values between the oldest cohort (onset 1961-1965) and the following cohorts are indicated in brackets

The prevalence of microalbuminuria remained at the same level from the first to the last investigation and varied from $5.7 \%$ to $11.9 \%$ in the patients diagnosed with diabetes between 1966 and 1985. There was an increase in the cohort 1961 to 1965 from 8.6\% to $21.2 \%$ but this was not statistically significant (Fig. 2b).

Six patients had received kidney transplants. All these patients belonged to the cohort with onset between 1961 and 1965.

The mortality rate was high, especially in the oldest cohort (Table 2). Of the 25 deaths, 7 were directly caused by nephropathy and uraemia. The mortality was highest among the patients with nephropathy, 12 (33.3\%) compared with $13(5.7 \%)$ for the patients without nephropathy.

\section{Discussion}

We studied a total population and managed to trace nearly all the patients with Type 1 diabetes diagnosed in childhood during the period between 1961 and 1985. When the patients were divided into 5-year cohorts according to the time of diagnosis, there was a declining trend in the cumulative proportion of severe retinopathy after 25 to 30 years of diabetes. Furthermore the previously reported marked decrease in the cumulative proportion of diabetic nephropathy persisted [8]. 
Table 2. Mortality in a population of patients with Type 1 diabetes diagnosed in childhood

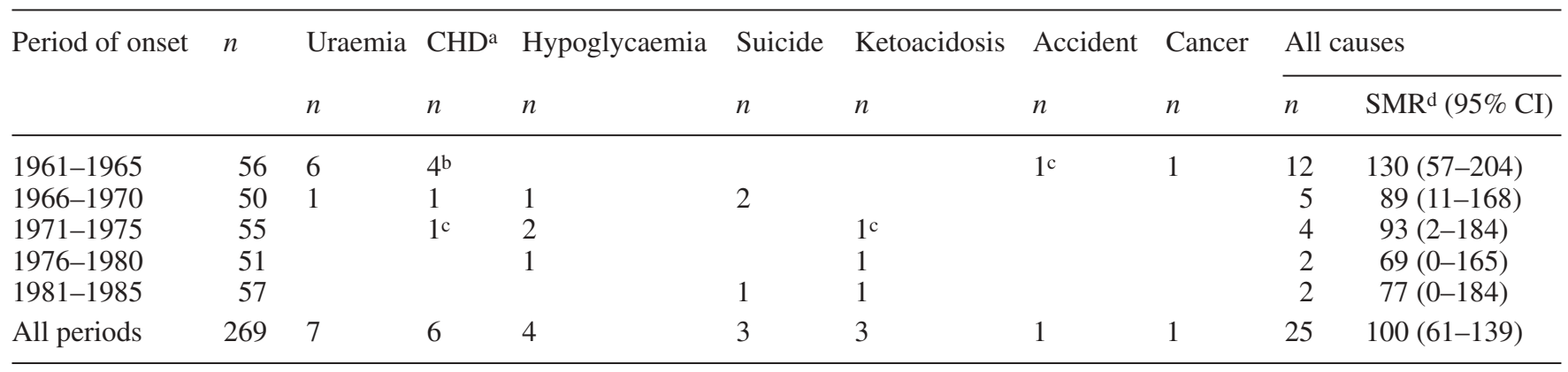

${ }^{a}$ CHD Coronary heart disease. ${ }^{b}$ Two of the patients had diabetic nephropathy. ${ }^{c}$ The patient had diabetic nephropathy. ${ }^{\mathrm{d}}$ SMR, standardised mortality ratio

We defined severe retinopathy as laser-treated retinopathy, because it is more definite than just proliferative retinopathy or macular oedema. It is possible that the indications for laser treatment have changed in the direction of more liberal indications during the past several years. This tends to overestimate the cumulative proportion in the younger cohorts compared with the older ones. The cumulative incidence of severe retinopathy is reported to be high in different studies from different diabetes centres and populations. Our figures for the oldest cohort with a cumulative proportion of nearly $60 \%$ after 35 years duration are similar to other studies $[12,13]$. We found a clear decrease of cumulative proportion for the younger cohorts. This decrease appeared 5 years later compared with the decrease of nephropathy. To our knowledge, this has not been previously reported for an unselected population with diabetes beginning in childhood. In a study from Denmark with follow-up until the year 2000, they also found a declining trend with increasing calendar year of diagnosis [14]. The patients were older at diagnosis and the study was clinic-based. Severe retinopathy, defined as proliferative retinopathy, had decreased to $12.5 \%$ after 20 years diabetes duration for the cohort with diagnosis between 1979 and 1984. The decrease appeared about 10 years later compared with our study. In our population, severe retinopathy, defined as laser-treated, had decreased to $14.7 \%$ already in the cohort diagnosed between 1966 and 1970.

Our definition of nephropathy as persistent proteinuria was the same as in older studies and makes it possible to compare the results, even if it is difficult to compare studies with different designs. Cross-sectional prevalence studies do not give results comparable with prospective studies with analysis of incidence rates. Prevalence studies tend to give lower figures after long-term follow-up of nephropathy. A considerable proportion of the patients die prematurely, as in our study [15]. It is also difficult to compare unselected population studies with hospital-based studies, which can be biased. However, the cumulative proportion of nephropathy of $32 \%$ after 30 years diabetes duration in the oldest cohort is comparable with results from other studies published in the 1980s and earlier $[13,16,17]$. A clinic-based study from Copenhagen in 1991 showed unchanged incidence [18]. Over the last several years however, some studies have been published which also show a declining trend. At followup in 1999 a study from Wales found a prevalence of nephropathy of $19 \%$ after 15 to 29 years of diabetes duration [19]. In the EuroDiab Study in 1990, the prevalence was at the same level, $18 \%$ after 20 to 24 years disease duration [20]. A new follow-up from the Copenhagen area in 2000 showed a marked decrease of the cumulative incidence of nephropathy to $13.7 \%$ after 20 years of diabetes duration [14]. The decrease was observed in the cohort with onset of diabetes between 1979 and 1984, that is, 10 to 15 years later than in our study. A Swedish population study completed in 1999 reported a cumulative incidence of macroalbuminuria of $12 \%$ after an average diabetes duration of 29 years [21].

Our study did not show a decrease of background retinopathy. Older studies have shown that almost every patient has developed background retinopathy after 20 to 30 years of diabetes duration $[12,13]$. On the other hand, the DCCT study showed that it was possible to prevent even background retinopathy with intensive therapy and better metabolic control [6]. An explanation in our population could be that the metabolic control was good enough to prevent more severe retinopathy, but did not affect milder forms. Background retinopathy is often clinically less important, and milder forms are reversible while the prognostic value is difficult to estimate [22, 23, 24]. We need longer follow-up before we can draw conclusions about whether it is possible to prevent severe retinopathy or only postpone it.

In older studies microalbuminuria was considered a very strong predictor of diabetic nephropathy $[25,26$, 27]. The prevalence of microalbuminuria was much higher in these studies than in our study (17-36\% compared with 6-12\%), even though their definitions were often stricter with microalbuminuria in repeated urine samples. Later studies from the 1990s have shown a better prognosis with about $30-60 \%$ of the 
patients reverting to normoalbuminuria $[28,29,30$, 31]. Still, microalbuminuria is a risk factor and about $20 \%$ of the patients with microalbuminuria will develop overt nephropathy within 7 to 10 years. The low prevalence of microalbuminuria in our study suggests that the incidence of nephropathy will not increase substantially in the coming years. The persistent decrease of nephropathy after 25 to 30 years with diabetes and the low prevalence of microalbuminuria suggest that nephropathy has been prevented and not just postponed in our population.

Some patients died before developing complications, but it is unlikely that this has influenced the results. The mortality was high in the oldest cohort (diagnosis between 1961and 1965) due to nephropathy as was also found in other studies $[15,32]$. In the younger cohorts mortality was lower than expected [33]. This was mainly attributable to a decrease in nephropathy as a cause of death. Altogether, seven patients died from hypoglycaemia or ketoacidosis with no obvious differences between the cohorts in this small sample.

In our previous study we found a strong correlation between the cumulative proportion of both nephropathy and retinopathy and glycaemic control [9]. A possible explanation for the better prognosis over the last few decades is better metabolic control from the beginning in the younger cohorts. Further analysis of the material will show if this is the primary explanation. Other factors like smoking habits and blood pressure level may also be of importance. The use of ACE inhibitors and other antihypertensive medicines has convincingly been shown to retard the progress of diabetic nephropathy [34]. In our population the use of antihypertensive treatment had increased during the 1990s, which could have contributed to the declining trend of nephropathy. The declining incidence of nephropathy was, however, noticed already at the follow-up in 1990, before the more widespread use of this treatment. It is therefore unlikely that antihypertensive therapy is an important explanation for the observed decrease in nephropathy.

In conclusion, we were able to demonstrate a declining incidence of both severe retinopathy and nephropathy over the last few decades among patients with diabetes duration between 25 and 30 years. The study suggests that with modern diabetes care it is possible in an unselected population of Type 1 diabetes to prevent both severe diabetic retinopathy and nephropathy.

Acknowledgements. We thank Mats Fredriksson, $\mathrm{PhD}$, for statistical advice and Fredrik Forsberg for skilful help with the computer and the figures. We are also grateful to colleagues all over Sweden, who helped us with patient data and hospital records. This study was supported by the Swedish Medical Research Council (MFR) K99-72X-11242-05A, the Swedish Child Diabetes Foundation (Barndiabetesfonden), the Swedish Diabetes Association and the Söderberg Foundation.

\section{References}

1. Gabbay KH (1976) Editorial: Glycosylated hemoglobin and diabetic control. N Engl J Med 295:443-444

2. Walford S, Gale EA, Allison SP, Tattersall RB (1978) S elf-monitoring of blood-glucose. Improvement of diabetic control. Lancet 1:732-735

3. Pickup JC, Keen H, Viberti GC et al. (1980) Continuous subcutaneous insulin infusion in the treatment of diabetes mellitus. Diabetes Care 3:290-300

4. Dahl-Jorgensen K, Brinchmann-Hansen O, Hanssen KF et al. (1986) Effect of near normoglycaemia for two years on progression of early diabetic retinopathy, nephropathy, and neuropathy: the Oslo study. Br Med J (Clin Res Ed) 293:1195-1199

5. Anonymous (1993) The effect of intensive treatment of diabetes on the development and progression of long-term complications in insulin-dependent diabetes mellitus. The Diabetes Control and Complications Trial Research Group. N Engl J Med 329:977-986

6. The Diabetes Control and Complications Trial/Epidemiology of Diabetes Interventions and Complications Research Group (2002) Effect of intensive therapy on the microvascular complications of Type 1 diabetes mellitus. JAMA 287:2563-2569

7. Reichard P, Pihl M, Rosenqvist U, Sule J (1996) Complications in IDDM are caused by elevated blood glucose level: the Stockholm Diabetes Intervention Study (SDIS) at 10-year follow up. Diabetologia 39:1483-1488

8. Bojestig M, Arnqvist HJ, Hermansson G, Karlberg BE, Ludvigsson J (1994) Declining incidence of nephropathy in insulin-dependent diabetes mellitus. N Engl J Med 330:15-18

9. Bojestig M, Arnqvist HJ, Karlberg BE, Ludvigsson J (1998) Unchanged incidence of severe retinopathy in a population of Type 1 diabetic patients with marked reduction of nephropathy. Diabet Med 15:863-869

10. No authors listed (1994) Effect of intensive diabetes treatment on the development and progression of long-term complications in adolescents with insulin-dependent diabetes mellitus: Diabetes Control and Complications Trial. Diabetes Control and Complications Trial Research Group. J Pediatr 125:177-188

11. Altman D (1991) Practical statistics for medical research. Chapman \& Hall/CRC, London

12. Klein R, Klein BE, Moss SE, Davis MD, Demets DL (1984) The Wisconsin epidemiologic study of diabetic retinopathy. II. Prevalence and risk of diabetic retinopathy when age at diagnosis is less than 30 years. Arch Ophthalmol 102:520-526

13. Orchard TJ, Dorman JS, Maser RE et al. (1990) Prevalence of complications in IDDM by sex and duration. Pittsburgh Epidemiology of Diabetes Complications Study II. Diabetes 39:1116-1124

14. Hovind P, Tarnow L, Rossing K et al. (2003) Decreasing incidence of severe diabetic microangiopathy in Type 1 diabetes. Diabetes Care 26:1258-1264

15. Borch-Johnsen K, Andersen PK, Deckert T (1985) The effect of proteinuria on relative mortality in Type 1 (insulindependent) diabetes mellitus. Diabetologia 28:590-596

16. Kofoed-Enevoldsen A, Borch-Johnsen K, Kreiner S, Nerup J, Deckert T (1987) Declining incidence of persistent proteinuria in Type I (insulin-dependent) diabetic patients in Denmark. Diabetes 36:205-209

17. Krolewski AS, Warram JH, Christlieb AR, Busick EJ, Kahn CR (1985) The changing natural history of nephropathy in Type I diabetes. Am J Med 78:785-794 
18. Rossing P, Rossing K, Jacobsen P, Parving HH (1995) Unchanged incidence of diabetic nephropathy in IDDM patients. Diabetes 44:739-743

19. Harvey JN, Rizvi K, Craney L, Messenger J, Shah R, Meadows PA (2001) Population-based survey and analysis of trends in the prevalence of diabetic nephropathy in Type 1 diabetes. Diabet Med 18:998-1002

20. Lloyd CE, Stephenson J, Fuller JH, Orchard TJ (1996) A comparison of renal disease across two continents; the epidemiology of diabetes complications study and the EURODIAB IDDM Complications Study. Diabetes Care 19:219-225

21. Dahlquist G, Stattin EL, Rudberg S (2001) Urinary albumin excretion rate and glomerular filtration rate in the prediction of diabetic nephropathy; a long-term follow-up study of childhood onset Type-1 diabetic patients. Nephrol Dial Transplant 16:1382-1386

22. Feman SS (1994) The natural history of the first clinically visible features of diabetic retinopathy. Trans Am Ophthalmol Soc 92:745-773

23. Hellstedt T, Immonen I (1996) Disappearance and formation rates of microaneurysms in early diabetic retinopathy. Br J Ophthalmol 80:135-139

24. Klein R, Klein BE, Moss SE, Cruickshanks KJ (1998) The Wisconsin Epidemiologic Study of Diabetic Retinopathy: XVII. The 14-year incidence and progression of diabetic retinopathy and associated risk factors in Type 1 diabetes. Ophthalmology 105:1801-1815

25. Mogensen CE, Christensen CK (1984) Predicting diabetic nephropathy in insulin-dependent patients. N Engl J Med 311:89-93
26. Parving HH, Oxenboll B, Svendsen PA, Christiansen JS, Andersen AR (1982) Early detection of patients at risk of developing diabetic nephropathy. A longitudinal study of urinary albumin excretion. Acta Endocrinol (Copenh) 100:550-555

27. Viberti GC, Hill RD, Jarrett RJ, Argyropoulos A, Mahmud U, Keen H (1982) Microalbuminuria as a predictor of clinical nephropathy in insulin-dependent diabetes mellitus. Lancet 1:1430-1432

28. Almdal T, Norgaard K, Feldt-Rasmussen B, Deckert T (1994) The predictive value of microalbuminuria in IDDM. A five-year follow-up study. Diabetes Care 17:120-125

29. Forsblom CM, Groop PH, Ekstrand A, Groop LC (1992) Predictive value of microalbuminuria in patients with insulindependent diabetes of long duration. BMJ 305:1051-1053

30. Bojestig M, Arnqvist HJ, Karlberg BE, Ludvigsson J (1996) Glycaemic control and prognosis in Type I diabetic patients with microalbuminuria. Diabetes Care 19:313-317

31. Tabaei BP, Al-Kassab AS, Ilag LL, Zawacki CM, Herman WH (2001) Does microalbuminuria predict diabetic nephropathy? Diabetes Care 24:1560-1566

32. Andersen AR, Christiansen JS, Andersen JK, Kreiner S, Deckert T (1983) Diabetic nephropathy in Type 1 (insulindependent) diabetes: an epidemiological study. Diabetologia 25:496-501

33. Nishimura R, Laporte RE, Dorman JS, Tajima N, Becker D, Orchard TJ (2001) Mortality trends in Type 1 diabetes. The Allegheny County (Pennsylvania) Registry 19651999. Diabetes Care 24:823-827

34. Mogensen CE (1998) Preventing end-stage renal disease. Diabet Med 15 [Suppl 4]:S51-S56 